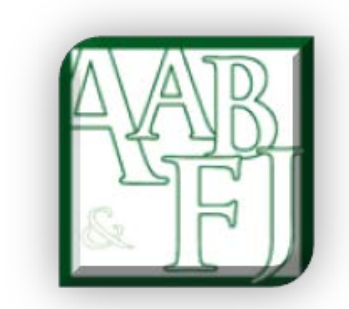

\title{
A Proposed Solution for the Chicken- Egg Dilemma in Pricing Currency Options
}

\author{
Ariful Hoque $^{1}$ \& Chandrasekhar Krishnamurti ${ }^{2}$
}

\section{Abstract}

The implied volatility (IV) estimation process suffers from an obvious chicken-egg dilemma: obtaining an unbiased IV requires the options to be priced correctly and calculating an accurate option price (OP) requires an unbiased IV. We address this critical issue in two steps. First, the Granger causality test is employed, which confirms the chicken-and-egg problem in the IV computing process. Secondly, the concept of "moneyness volatility (MV)" is introduced as an alternative to IV. MV is modelled based on an option's moneyness (OM) during the life of the option's contract. The F-test, Granger-Newbold test and DieboldMariano test results consistently show that MV outperforms IV in estimating the exchange rate volatility for pricing options. Further, these series of tests across six major currency options substantiate the validity as well as the reliability of the results. We posit that MV offers a unique solution for pricing currency options accurately.

Keywords: Currency options pricing, implied volatility, moneyness volatility, Granger causality test, Granger-Newbold

JEL Code: G13, G17

\footnotetext{
${ }^{1}$ Murdoch University

${ }^{2}$ University of Southern Queensland

Email:a.hoque@murdoch.edu.au
} 


\section{Introduction}

The pricing of currency options requires the volatility of the exchange rates. It is a key parameter in the pricing model and cannot be observed directly. Traders believe that IV is the best exchange rate volatility forecast, and this measure is widely used for pricing options. Using data from currency options, Scott and Tucker (1989) found that IV derived from currency options captures nearly 50 percent of the actual currency volatility. $\mathrm{Xu}$ and Taylor (1994) examine the informational efficiency of the currency options market in the Philadelphia Stock Exchange (PHLX). They studied four currencies (British pound, Mark, Yen and Swiss franc against the US dollar) over the January 1985 to January 1992 period and found that OPs contain incremental information about future volatilities. Jorion (1995) examined the predictive power of IV for Mark, Yen and Swiss franc against US dollar, traded in the Chicago Mercantile Exchange. Jorion's results suggest that IV outperforms statistical time-series models in terms of information content and predictive power. Christoffersen and Mazzotta (2005) used OTC currency options and found that IV provides a largely unbiased and fairly accurate forecast of the actual volatility one month and three months ahead. Chang and Tabak (2007) presented evidence that the IV, in the case of OPs, contains information that is not present in past returns for the Brazilian real exchange rate against the US dollar. All of the above evidence now favours the conclusion that IV is more informative than daily returns when measuring foreign exchange volatility.

Researchers also argue that there is a constraint faced in obtaining unbiased IV using market prices. The evidence of Kazantzis and Tessaromatis (2001) suggest that IV may be a biased representation of market expectations when OPs do not represent equilibrium market price. Pong et al. (2004) provide similar evidence. Finally, Ederington and Guan (2006) hold that the IV measure suffers from an obvious chicken-and-egg problem: the calculation of IV requires the option to be correctly priced, and the calculation of the appropriate OP requires an unbiased IV estimate.

Summing up, IV is the best predictor of exchange rate volatility for pricing currency options but the procedure to estimate the unbiased IV presents us with a chicken-egg dilemma. Our proposed solution to this dilemma is as follows. First, this critical issue is examined by employing the Granger causality (GC) test. The bilateral Granger causality confirms that the unbiased IV estimation process suffers from the chicken-and-egg problem. Second, the GC test results lead to development of the concept of "moneyness volatility (MV)" as an alternative to IV. Third, a "horse race" between our measure (MV) and IV is conducted. The results of the F-test, the Granger-Newbold test (1976) and the DieboldMariano test (1995) consistently show that MV outperforms IV in pricing currency options. This study finds that MV removes the pitfalls of IV in estimating the exchange rate volatility for pricing currency options correctly.

This reasearch contributes to the literature by providing a new volatility estimate for pricing currency options. The "moneyness volatility" which was developed recently has been shown to outperform IV when realised volatility is used as the benchmark. ${ }^{3}$ In this paper, the usefulness of MV is further validated utilising an option pricing framework.

The study is organised as follows. The next section explains the research methodology and describes the data used in this study. In Section 3, the results of empirical analysis is presented and discussed. The main findings are summarised in Section 4.

\footnotetext{
${ }^{3}$ Please see Hoque and Krishnamurti (2012).
} 


\section{Methodology and Data}

First, the methodology is described, followed by the description of data used in this study.

\subsection{Methodology}

The methodology is divided into four sub-sections: the IV, the Granger causality test, the moneyness volatility and pricing options.

\subsubsection{IMPLIED VOLATILITY}

The volatility measure implied in OPs is called IV. This study derives IV from the currency option pricing model. Black and Scholes (1973) developed a closed-form solution for pricing European non-dividend-paying stock options. This model is extended by Merton (1973) for continuous dividends. Because the interest gained on holding a foreign currency is equivalent to a continuously paid dividend on a stock, the Merton version of the Black and Scholes (BS) model can be applied to foreign securities. To value currency options, stock prices are substituted for exchange rates. The pricing of European call and put currency options follows equations (1) and (2), respectively, and are now described.

The European call and put currency options are priced as in equations (1) and (2), respectively shown below:

$$
\begin{aligned}
& C_{t}=S_{t} e^{-R_{t, f} T} N\left(d_{1, t}\right)-X_{t} e^{-R_{t, d} T} N\left(d_{2, t}\right), \\
& P_{t}=X_{t} e^{-R_{t, d} T} N\left(-d_{2, t}\right)-S_{t} e^{-R_{t, f} T} N\left(-d_{1, t}\right),
\end{aligned}
$$

where $d_{1, t}=\frac{\ln \left(S_{t} / X_{t}\right)+\left(R_{t, d}-R_{t, f}+\sigma_{t}^{2} / 2\right) \Gamma}{\sigma_{t} \sqrt{T}}$,

$$
d_{2, t}=\frac{\ln \left(S_{t} / X_{t}\right)+\left(R_{t, d}-R_{t, f}-\sigma_{t}^{2} / 2\right) T}{\sigma_{t} \sqrt{T}}=d_{1, t}-\sigma_{t} \sqrt{T} .
$$

The descriptions of notations used in equations (1) and (2) are as follows:

$t=$ option trading time

$C_{t}=$ call price in domestic currency at $t$

$P_{t}=$ put price in domestic currency at $t$

$S_{t}=$ exchange rate at $t$

$X_{t}=$ call and put strike price in domestic currency at $t$

$R_{t, d}=$ risk-free domestic currency interest rate at $t$

$R_{t, f}=$ risk-free foreign currency interest rate at $t$

$\sigma_{t}=$ exchange rate volatility at $t$

$N$ = cumulative normal distribution function

$T=$ option expiration time

IV is that value of $\sigma_{t}$, when substituted into equations (1) and (2) gives the market call and put option price, respectively. It is not possible to invert equations (1) and (2) with respect to the $\sigma_{\mathrm{t}, \text {. }}$ Alternatively, an iterative search procedure can be used to find the IV for given options market prices. Two approaches are popular in the literature and are considered here (Press et al. 1992). These are the Newton-Raphson and Dekker-Brent method respectively. The first approach, the Newton-Raphson method utilises derivative information and converges at quadratic speed. The Dekker-Brent method applies a blend of the bisection, secant and inverse quadratic interpolation methods and convergence is assured. Although the 
Newton-Raphson method is faster in processing it is less robust than the Dekker-Brent method. Due to the considerations of robustness, the Dekker-Brent method is often chosen over the Newton-Raphson method in practice (Li 2008). Another drawback of the NewtonRaphson method is that it might cause machine failure arising from division by a small number or it might drive the next iteration beyond a bracketed region. Following earlier work, this paper uses the Dekker-Brent method.

To take advantage of the Dekker-Brent method, the Financial Toolbox of MATLAB (R2009a version) which contains the built-in function "blsimpv" is employed to obtain an unbiased IV. The function "blsimpv" consists of equations (1) and (2) to calculate the IV for call price $\sigma_{t, I V C}$ and the IV for put price $\sigma_{t, I V P}$, as in equations (3) and (4), respectively. Gospodinov, Gavala and Jiang (2006) suggest that an unbiased IV can be extracted from near-the-money options. Hoque et al. (2008) find that the mispricing of options is relatively low for at-the-money (ATM) options. We thus use the ATM call price $\mathrm{C}_{\mathrm{t}, \mathrm{ATM}}$ and the ATM put price $\mathrm{P}_{\mathrm{t}, \mathrm{ATM}}$ as inputs for equations (3) and (4), respectively, with the default upper bound limit for IV at $1000 \%$ per annum and termination tolerance at 0.0001 .

$$
\begin{aligned}
& \sigma_{t, I V C}=\operatorname{blsimpv}\left(S_{t}, X_{t}, R_{t, d}, T, C_{t, A T M}, \text { Limit, } R_{t, f}, \text { Tolerance, }\{\text { 'call' }\}\right) \\
& \sigma_{t, I V P}=\operatorname{blsimpv}\left(S_{t}, X_{t}, R_{t, d}, T, P_{t, A T M}, \text { Limit, } R_{t, f}, \text { Tolerance, }\{\text { ' put' }\}\right)
\end{aligned}
$$

There is no appropriate weighting scheme that can be applied for $\sigma_{\mathrm{t}, \mathrm{IVC}}$ and $\sigma_{\mathrm{t}, \mathrm{IVP}}$ to estimate IV. Jorion (1995) computed IV as the arithmetic average of that obtained from the two closest ATM call and put options. This study thus estimates the annualised IV $\sigma_{t, I V}$ on any given day as the arithmetic average of $\sigma_{t, I V C}$ and $\sigma_{t, I V P}$,

$$
\sigma_{t, I V}=\frac{\sigma_{t, I V C}+\sigma_{t, I V P}}{2}
$$

\subsubsection{GRANGER CAUSALITY TEST}

The Granger causality test is employed to confirm that the unbiased IV estimation process suffers from the chicken-egg dilemma. It examines the options price (OP) that causes the IV and the IV that causes OP by equations (6) and (7), respectively,

$$
\begin{aligned}
& I V=\sum_{i=1}^{m} \alpha_{i} I V_{t-i}+\sum_{i=1}^{m} \beta_{i} O P_{t-i}+\varepsilon_{t}, \\
& O P=\sum_{i=1}^{m} \alpha_{i} O P_{t-i}+\sum_{i=1}^{m} \beta_{i} I V_{t-i}+\varepsilon_{t},
\end{aligned}
$$

where $m$ represents the number of lags and the OP is either the call price (CP) or the put price (PP). The null hypotheses of equations (6) and (7) are that "OP does not cause IV" and "IV does not cause OP”, respectively.

\subsubsection{MONEYNESS VOLATILITY}

The moneyness volatility (MV) is designed to estimate the exchange rate volatility. The options' moneyness (OM) identifies whether or not an option is profitable for immediate exercise. An option is in-the-money (ITM), at-the-money (ATM) and out-of-the-money (OTM) when it provides a profit, neither a profit nor a loss, and a loss, respectively. If a call 
and a put option have the same trading day $t$ and strike price $X_{t}$, their moneyness (ITM, ATM, OTM) from the next trading day $(t+1)$ to the options maturity day $(T)$ can be expressed as

$M_{t+i}=\left(\frac{X_{t}}{S_{t+i}}\right)$,

where, $\mathrm{i}=1,2,3 \ldots, \mathrm{T}$-t and $\mathrm{S}_{\mathrm{t}+\mathrm{i}}$ is the future spot price. In equation (8), a call (put) is ITM (OTM) for $\mathrm{M}_{\mathrm{t}+1}<1$; A call (put) is ATM (ATM) for $\mathrm{M}_{\mathrm{t}+1}=1$; A call (put) is OTM (ITM) for $M_{t+1}>1$. Equation (8) measures the moneyness of the call and the put option simultaneously with equal magnitude. It means that if the call is ITM by 5 US dollars, the put is OTM by 5 US dollars, the same amount. Because the future spot price $S_{t+i}$ in equation (8) is not available on trading day t, we can use the forward price as an unbiased predictor of the future spot price $S_{t+i}$. Further, due to the non-synchronised forward and options maturity date, the futures price $F_{t}$ can be the best proxy of the forward price. The future spot price $S_{t+i}$ in equation (8) is thus replaced with the futures price $F_{t+i}$ as

$M_{t+i}=\left(\frac{X_{t}}{F_{t+i}}\right)$.

The combined daily moneyness return of the call and the put option is $R_{t+i}=\ln \left(M_{t+i}\right)$.

The combined moneyness variance of the call and put option over the remaining life of the option contract (i.e., from $t+1$ to $\mathrm{T}$ ) is

$V_{t+1, T}=\frac{1}{T-t} \sum_{i=1}^{T-t}\left(R_{t+i}-\bar{R}\right)^{2}$.

Because the call and put OM occurs concurrently with the same magnitude, the daily moneyness volatility $\sigma_{\mathrm{t}, \mathrm{DMV}}$ is half of the standard deviation of the combined moneyness variance as

$\sigma_{t, M V D}=\left(\sqrt{V_{t+1, T}}\right) / 2$

As daily data of trading days are used to provide the MV estimate, days when the exchange is closed are ignored, and the MV per annum is

$\sigma_{t, M V}=\sqrt{D \times \sigma_{t, M V D}}$,

where D is 252 trading days per year, consistent with the normal assumption of the options market.

The moneyness volatility approach was pioneered in Hoque and Krishnamurti (2012). Since this is a relatively new approach, the salient details have been described above for the convenience of the reader. 


\subsubsection{PRICING OPTIONS}

Kazantzis and Tessaromatis (2001) suggest that the IV is generally better than historic volatility forecasts for horizons ranging from one day to three months. This study includes only a one-day-ahead options price estimation process. The values of $\sigma_{\mathrm{t}, \mathrm{IV}}$ and $\sigma_{\mathrm{t}, \mathrm{MV}}$ are used to evaluate the performance of IV and MV, respectively, for pricing one-day-ahead options appropriately. The MATLAB built-in function "blsprice" embeds equations (1) and (2) to calculate the call and put price, respectively. The $\sigma_{t, I V}$ from equation (5) is used as input for the function "blsprice" to calculate the implied-volatility call price $\mathrm{C}_{\mathrm{t}, \mathrm{IV}}$ and the impliedvolatility put price $\mathrm{P}_{\mathrm{t}, \mathrm{IV}}$ as

$$
\left\lfloor C_{t, I V}, P_{t, I V}\right\rfloor_{t+1}=\operatorname{blsprice}\left(S_{t+1}, X_{t+1}, R_{t+1, d}, T, \hat{\sigma}_{t, I V}, R_{t+1, f}\right) \text {. }
$$

Similarly, the $\sigma_{t, M V}$ from equation (9) is used to estimate the moneyness-volatility call price $\mathrm{C}_{\mathrm{t}, \mathrm{MV}}$ and the moneyness-volatility put price $\mathrm{P}_{\mathrm{t}, \mathrm{MV}}$ as

$$
\left\lfloor C_{t, M V}, P_{t, M V}\right\rfloor_{t+1}=\text { blsprice }\left(S_{t+1}, X_{t+1}, R_{t+1, d}, T, \hat{\sigma}_{t, M V}, R_{t+1, f}\right) .
$$

Next, the MV and IV performance is assessed to measure exchange rate volatility for pricing the call and put option. The F-test, Granger-Newbold test and Diebold-Mariano test are employed in their ( $\mathrm{MV}$ and IV) performance evaluation process. Because the test procedure for the call is analogous to that of the put, this study describes the methodology only for pricing the call option. The implied-volatility call pricing error $\xi_{\mathrm{t}, \mathrm{IVC}}$ is the difference between the implied-volatility call price $C_{t, I V}$, which is estimated by equation (10), and the ATM call market price $\mathrm{C}_{\mathrm{t}, \mathrm{ATM}}$. For $\mathrm{n}$ observations, the implied-volatility call pricing mean square error can be calculated as

$$
M S E_{t, I V C}=\frac{1}{n} \sum_{t=1}^{n} \xi_{t, I V C}^{2}
$$

Similarly, the moneyness-volatility call pricing mean square error for $\mathrm{n}$ observations can be calculated as

$$
M S E_{t, M V C}=\frac{1}{n} \sum_{t=1}^{n} \zeta_{t, M V C}^{2},
$$

where the moneyness-volatility call pricing error $\zeta_{\mathrm{t}, \mathrm{MVC}}$ is calculated as the difference between the moneyness-volatility call price $C_{t, M V}$, which is estimated by equation (11), and the ATM call's market price $\mathrm{C}_{\mathrm{t}, \mathrm{ATM}}$. The F-test for the call is modelled as in equation (12) for $n$ degrees of freedom to test the equality of $\mathrm{MSE}_{\mathrm{t}, \mathrm{IVC}}$ and $\mathrm{MSE}_{\mathrm{t}, \mathrm{MVC}}$

$$
F_{t, C}=\frac{M S E_{t, I V C}}{M S E_{t, M V C}} .
$$

The violation of any one of the following assumptions means that the ratio of the MSEs in equation (12) does not have an F-distribution.

(1) The pricing errors have zero mean and are normally distributed 
(2) The pricing errors are serially uncorrelated

(3) The pricing errors are contemporaneously uncorrelated with each other

If the first two assumptions above are valid, the Granger and Newbold (1976) is the appropriate test with accommodating the problem of contemporaneously correlated pricing errors. If $\mathrm{x}_{\mathrm{t}}=\left(\xi_{\mathrm{t}, \mathrm{IVC}}+\zeta_{\mathrm{t}, \mathrm{MVC}}\right), \mathrm{z}_{\mathrm{t}}=\left(\xi_{\mathrm{t}, \mathrm{IVC}}-\zeta_{\mathrm{t}, \mathrm{MVC}}\right)$ and $\mathrm{r}_{\mathrm{xz}}$ is the correlation between $\left\{\mathrm{x}_{\mathrm{t}}\right\}$ and $\left\{z_{t}\right\}$, the Granger-Newbold (GN) statistic for the call is given in equation (13) which has a tdistribution with n-1 degrees of freedom,

$$
G N_{t, C}=\frac{r_{x z}}{\sqrt{\left(1-r_{x z}^{2}\right) /(n-1)}}
$$

To relax all of the three above assumptions, the test proposed by Diebold and Mariano (1995) is the ideal alternative, as it extends the Granger-Newbold (1976) test. In the Diebold and Mariano (1995) test, the differential loss from $\mathrm{MSE}_{\mathrm{t}, \mathrm{IVC}}$ and $\mathrm{MSE}_{\mathrm{t}, \mathrm{MVC}}$ is estimated as in equation (14):

$d_{t}=\left(M S E_{t, I V C}-M S E_{t, M V C}\right)$.

There is a high probability that the cost of a pricing error rises extremely quickly in the size of the error. In such a circumstance, the loss function might be best represented by the call pricing mean square error raised to the fourth power, and the differential loss from $\mathrm{MSE}_{\mathrm{t}, \mathrm{IVC}}$ and $\mathrm{MSE}_{\mathrm{t}, \mathrm{MVC}}$ can be estimated by

$$
d_{t}=\left(M S E_{t, I V C}^{4}-M S E_{t, M V C}^{4}\right) .
$$

If the serial correlation in the $\left\{d_{t}\right\}$ series obtained from equation (15) is experienced, the differential loss from $\mathrm{MSE}_{\mathrm{t}, \mathrm{IVC}}$ and $\mathrm{MSE}_{\mathrm{t}, \mathrm{MVC}}$ should be estimated by equation (14). The mean differential loss can be calculated as

$\bar{d}=\frac{1}{n} \sum_{t=1}^{n}\left[M S E_{t, I V C}^{4}-M S E_{t, M V C}^{4}\right]$.

Under the null hypothesis of equal one-day-ahead pricing errors accuracy, the value of $\bar{d}$ is zero. The original Diebold-Mariano (DM) statistic for the call is given by

$D M_{t, C}=\frac{\bar{d}}{\sqrt{\operatorname{var}(\bar{d})}}$, where $\operatorname{var}(\bar{d})=\frac{1}{n-1} \operatorname{var}\left(d_{t}\right)$

Equation (16) follows a t-distribution with $(n-1)$ degrees of freedom. The objective of these series of tests is also to check the validity of the overall results. All of the above three tests (F-test, GN test and DM test) are also employed to evaluate the performance of IV and MV for pricing put options. 


\subsection{Data Description}

This study includes the six major currency options of the Australian dollar (AUD), the British pound (BP), the Canadian dollar (CAD), the Euro (EUR), the Japanese yen (JPY) and the Swiss franc (SF) of the World Currency Options (WCO) market, traded on the PHLX. The WCO is a new class of currency options launched by the PHLX on July 24, 2007(Offshore A-Letter 2007). These options mature on a monthly basis. Before the launch of the WCO market, currency options on the PHLX were traded on a quarterly basis with the following maturity months: March, June, September and December. Each currency option contract represents 10,000 units of the underlying currency, except for the Japanese yen $(1,000,000)$. A unique feature of the WCO is the smaller contract size of currency options as compared to existing option contracts. Thus WCO has opened up the world of currency trading to investors with smaller amounts to invest. As a consequence of these new features, the volume of trading has soared, thereby increasing the efficiency of OPs (Hoque 2010).

Since data are only available from 18 December 2007 in the DATASTREAM, in this study, the ATM put-call pairs and the ATM strike price for the period starting from 24 December 2007 to 18 December 2009 are used. There are thus a total number of 520 daily observations for each sample currency. Because the options expire on the third Saturday of each month, the sample period begins (24 December 2007, Monday) after the options' expiry date of 21 December 2007, and the sample period ends (18 December 2009, Friday) before the options expiry date of 19 December 2009. The sample currency options' maturity is one month. The data set consists of the daily closing spot exchange rates, the sample currency futures' settle price and daily risk-free interest rates for all currencies, including the US dollar, for the sample period, all of which are obtained from DATASTREAM. All of these data are available on request.

\section{Empirical Analysis}

The empirical analysis starts with a discussion of the time-series properties of the call, put strike and spot price used in this study. Table 1 shows the descriptive statistics of the variables. For most of the data series, the mean and median values are close, and the skewness parameter indicates non-symmetric distributions. However, the Jarque-Bera (JB) normality test rejects the approximately normal distribution assumption for sample currencies. In Table 1, the mean values of the ATM call price are reasonably different from the ATM put price for all currencies except CAD and JPY. Further, the same mean values of the strike price and the spot price ensure that the sample currency options are traded ATM.

The Granger causality tests impose the restriction that the variables need to be stationary. The standard Augmented Dickey-Fuller (ADF) (Dickey \& Fuller 1979), PhillipsPerron (P-P) (Phillips \& Perron 1988) and Kwiatkowski-Phillips-Schmidt-Shin (KPSS) (Kwiatkowski et al. 1992) tests are thus applied to identify the presence of unit roots in CP (call price), PP (put price) and IV data series. The ADF test accommodates serial correlation and time trending by explicitly specifying the autocorrelation structure. The P-P test accommodates heteroskedasticity and autocorrelation using the non-parametric method. Phillips and Perron (1988) show that the P-P test has stronger power than the ADF test under a wide range of circumstances. This study also includes the KPSS test, which employs a different approach than that of ADF and P-P to determine the presence of unit root in the sample data series. 
Table 1

Descriptive Statistics of Variables

\begin{tabular}{|c|c|c|c|c|c|}
\hline \multirow[t]{2}{*}{ Currency } & \multirow{2}{*}{$\begin{array}{l}\text { Statistical } \\
\text { measures }\end{array}$} & \multicolumn{4}{|c|}{ Variables } \\
\hline & & ATM call price & ATM put price & strike price & spot price \\
\hline \multirow[t]{5}{*}{ AUD } & mean & 0.0159 & 0.0188 & 0.8222 & 0.8222 \\
\hline & median & 0.0153 & 0.0175 & 0.8450 & 0.8437 \\
\hline & skewness & 1.4012 & 1.8769 & -0.4109 & -0.4085 \\
\hline & kurtosis & 6.3424 & 9.3431 & 1.7462 & 1.7447 \\
\hline & $\mathrm{JB}$ & $412.21^{* *}$ & $1177.1^{* *}$ & $48.687 * *$ & $48.602 * *$ \\
\hline \multirow[t]{5}{*}{$\mathrm{BP}$} & mean & 0.0260 & 0.0284 & 1.7153 & 1.7153 \\
\hline & median & 0.0238 & 0.0268 & 1.6500 & 1.6503 \\
\hline & skewness & 0.9765 & 1.1895 & 0.1481 & 0.1497 \\
\hline & kurtosis & 3.6126 & 4.6814 & 1.5688 & 1.5680 \\
\hline & JB & $90.778 * *$ & $183.87 * *$ & $46.284 * *$ & $46.374 * *$ \\
\hline \multirow[t]{5}{*}{ CAD } & mean & 0.0158 & 0.0159 & 0.9126 & 0.9126 \\
\hline & median & 0.0151 & 0.0155 & 0.9325 & 0.9327 \\
\hline & skewness & 0.7034 & 0.8368 & -0.3670 & -0.3675 \\
\hline & kurtosis & 3.3424 & 3.7419 & 1.7391 & 1.7406 \\
\hline & JB & $45.420 * *$ & $72.608 * *$ & $46.124 * *$ & $46.069 * *$ \\
\hline \multirow[t]{5}{*}{ EUR } & mean & 0.0223 & 0.0232 & 1.4334 & 1.4334 \\
\hline & median & 0.0203 & 0.0219 & 1.4425 & 1.4432 \\
\hline & skewness & 0.9098 & 0.9751 & -0.1870 & -0.1854 \\
\hline & kurtosis & 3.3653 & 3.8961 & 2.0025 & 1.9994 \\
\hline & $\mathrm{JB}$ & $74.637 * *$ & $99.801^{* *}$ & $24.589 * *$ & $24.671^{* *}$ \\
\hline \multirow[t]{5}{*}{ JPY } & mean & 0.00018 & 0.00017 & 0.00987 & 0.00987 \\
\hline & median & 0.00017 & 0.00016 & 0.00980 & 0.00979 \\
\hline & skewness & 1.1764 & 1.7036 & 0.14773 & 0.14860 \\
\hline & kurtosis & 4.6739 & 7.1998 & 1.79975 & 1.80439 \\
\hline & $\mathrm{JB}$ & $180.652 * *$ & $633.680 * *$ & $33.104^{* *}$ & $32.8856 * *$ \\
\hline \multirow[t]{5}{*}{ SF } & mean & 0.0149 & 0.0146 & 0.9240 & 0.9240 \\
\hline & median & 0.0145 & 0.0144 & 0.9200 & 0.9221 \\
\hline & skewness & 1.0039 & 0.9897 & -0.1756 & -0.1758 \\
\hline & kurtosis & 5.1300 & 4.7762 & 2.0118 & 2.0197 \\
\hline & JB & $185.64 * *$ & $153.25 * *$ & $23.820 * *$ & $23.501 * *$ \\
\hline \multicolumn{6}{|c|}{$\begin{array}{l}\text { Notes: The Jarque-Bera (JB) statistic follows a chi-square distribution with two degrees } \\
\text { of freedom. The critical value of the chi-square distribution is } 5.99 \text { at the } 5 \% \text { level of } \\
\text { significance. The significance at the } 5 \% \text { level is denoted by } * * \text {. }\end{array}$} \\
\hline
\end{tabular}

The ADF, P-P and KPSS unit root tests are run on levels of the CP, PP and IV, and the test results are given in Table 2. The CP and PP for all currencies significantly reject the null hypothesis of unit root under the ADF, PP and KPSS tests. The IV also rejects the null hypothesis of unit roots at a high level of significance under both P-P and KPSS (British pound only P-P test) tests for all currency. The analysis in Table 2 indicates that the variables, $\mathrm{CP}, \mathrm{PP}$ and IV, are stationary for at least one of the unit root tests (ADF, P-P or KPSS).

After confirming that the variables are stationary, the Granger causality test is conducted to determine the presence and nature of causality between OP (options price) and IV. The selection of the number of lags in causality tests is an important practical issue. Conventional wisdom indicates that it is better to use more rather than fewer lags (Quantitative Micro Software 2007). 500 is considered to be the minimum degrees of freedom to run the Granger causality test, while each sample currency consists of 520 data points. The maximum number of lags 20 (520 to 500) is thus selected for the test. Further, to ensure that the results are not sensitive to the selection of the number of lags, we choose two different lagged lengths - 10 and 20, which are within the maximum number of lags (20). 
Table 2

Unit Root Tests on Levels

\begin{tabular}{|c|c|c|c|c|}
\hline \multirow[t]{2}{*}{ Currency } & \multirow[t]{2}{*}{ Tests } & \multicolumn{3}{|c|}{ Variables } \\
\hline & & Call Price (CP) & Put Price (PP) & $\begin{array}{l}\text { Implied Volatility } \\
\text { (IV) }\end{array}$ \\
\hline AUD & $\begin{array}{l}\text { ADF } \\
\text { PP } \\
\text { KPSS }\end{array}$ & $\begin{array}{c}-3.6893 * * * \\
-7.2754 * * * \\
0.5532 * * *\end{array}$ & $\begin{array}{c}-5.0514 * * * \\
-6.1991 * * * \\
0.3986 * * *\end{array}$ & $\begin{array}{c}-1.9811 \\
-7.6901^{* * *} \\
0.5493 * * *\end{array}$ \\
\hline $\mathrm{BP}$ & $\begin{array}{l}\text { ADF } \\
\text { PP } \\
\text { KPSS }\end{array}$ & $\begin{array}{c}-3.9049 * * * \\
-4.1771^{* * *} \\
0.6485^{* * *} \\
\end{array}$ & $\begin{array}{c}-4.627 * * * \\
-4.9137 * * * \\
0.4740 * * *\end{array}$ & $\begin{array}{c}-1.8668 \\
-7.8117^{* * *} \\
0.8140\end{array}$ \\
\hline CAD & $\begin{array}{l}\text { ADF } \\
\text { PP } \\
\text { KPSS } \\
\end{array}$ & $\begin{array}{c}-4.3663 * * * \\
-5.2045 * * * \\
0.4998 * * *\end{array}$ & $\begin{array}{c}-5.2453 * * * \\
-5.7365 * * * \\
0.4409 * * *\end{array}$ & $\begin{array}{c}-2.1373 \\
-7.8931^{* * *} \\
0.5874 * * *\end{array}$ \\
\hline EUR & $\begin{array}{l}\text { ADF } \\
\text { PP } \\
\text { KPSS } \\
\end{array}$ & $\begin{array}{c}-5.5581 * * * \\
-4.9114^{* * *} \\
0.6068 * * * \\
\end{array}$ & $\begin{array}{c}-4.7461^{* * *} \\
-4.8532^{* * *} \\
0.5296 * * * \\
\end{array}$ & $\begin{array}{c}-2.0115 \\
-7.7699 * * * \\
0.6011^{* * *} \\
\end{array}$ \\
\hline JPY & $\begin{array}{l}\text { ADF } \\
\text { PP } \\
\text { KPSS } \\
\end{array}$ & $\begin{array}{c}-5.0712 * * * \\
-6.6852 * * * \\
0.4395 * * * \\
\end{array}$ & $\begin{array}{c}-5.0257 * * * \\
-6.3295 * * * \\
0.4287 * * * \\
\end{array}$ & $\begin{array}{c}-2.4839 \\
-8.0695 * * * \\
0.4035 * * * \\
\end{array}$ \\
\hline $\mathrm{SF}$ & $\begin{array}{l}\text { ADF } \\
\text { PP } \\
\text { KPSS }\end{array}$ & $\begin{array}{l}-5.8357 * * * \\
-6.6945^{* * *} \\
0.4371^{* * *}\end{array}$ & $\begin{array}{c}-5.6220 * * * \\
-7.1103 * * * \\
0.4200 * * *\end{array}$ & $\begin{array}{c}-2.7022 * \\
-7.9485 * * * \\
0.3674 * * *\end{array}$ \\
\hline $\begin{array}{l}\text { the } \\
\text { test } \\
* * *\end{array}$ & $\begin{array}{l}d \\
0 \\
10\end{array}$ & $\begin{array}{l}\text { values for the } \\
\text { respectively. } \\
.3470 \text { at the } \\
1 \% \text { levels of }\end{array}$ & $\begin{array}{l}\text { nd PP tests ar } \\
\Lambda \text {-statistic cri } \\
\text { and } 10 \% \text { leve } \\
\text { ince, respecti }\end{array}$ & $\begin{array}{l}14,-2.86 \text { and }-2.56 \text { a } \\
\text { values for the KPS } \\
\text { spectively. *, ** anc }\end{array}$ \\
\hline
\end{tabular}

To determine whether OP (CP and PP) causes the IV, the Granger causality test was conducted using equation (6) for two null hypotheses: (1) CP does not "Granger-cause" the IV $(\mathrm{CP} \rightarrow \mathrm{IV})$, and (2) PP does not "Granger-cause" the IV (PP $\rightarrow \mathrm{IV})$. The test results are given in Table 3. For all currency, the P-values indicate that the null hypotheses (1) and (2) are firmly rejected for both lags 10 and 20. The test results identify the unidirectional Granger causality from OP to IV.

Table 3

Granger Causality Test for OP does not cause IV

\begin{tabular}{|c|c|c|c|c|c|c|c|c|}
\hline \multirow[t]{3}{*}{ Currency } & \multicolumn{4}{|c|}{$\mathrm{CP} \rightarrow \mathrm{IV}$} & \multicolumn{4}{|c|}{$\mathrm{PP} \rightarrow \mathrm{IV}$} \\
\hline & \multicolumn{2}{|c|}{$\begin{array}{c}m=10 \text { and } n= \\
510\end{array}$} & \multicolumn{2}{|c|}{$\begin{array}{l}m=20 \text { and } n= \\
500\end{array}$} & \multicolumn{2}{|c|}{$m=10$ and $n=510$} & \multicolumn{2}{|c|}{$m=20$ and $n=500$} \\
\hline & F-stat & P-value & F-stat & P-value & F-stat & P-value & F-stat & P-value \\
\hline AUD & 11.24 & 2.E-17 & 4.63 & 4.E-10 & 11.36 & 1.E-17 & 6.26 & 6.E-15 \\
\hline $\mathrm{BP}$ & 10.76 & 1.E-16 & 6.03 & 3.E-14 & 9.84 & 4.E-15 & 4.81 & 1.E-10 \\
\hline CAD & 9.55 & 1.E-14 & 4.51 & 9.E-10 & 10.08 & 2.E-15 & 4.25 & 5.E-09 \\
\hline EUR & 10.44 & 5.E-16 & 3.89 & 5.E-08 & 9.36 & 3.E-14 & 3.99 & 3.E-08 \\
\hline JPY & 5.69 & 4.E-08 & 2.05 & 0.0050 & 6.99 & 3.E-10 & 3.81 & 9.E-09 \\
\hline SF & 8.34 & 1.E-12 & 4.52 & 8.E-10 & 7.06 & 2.E-10 & 3.83 & 8.E-08 \\
\hline
\end{tabular}

To determine the unidirectional causality from IV to OP, the Granger causality test was performed for equation (7) with the two null hypotheses: (1) IV does not "Grangercause" the CP (IV $\rightarrow \mathrm{CP})$, and (2) IV does not "Granger-cause" the PP (IV $\rightarrow \mathrm{PP})$. The test results are shown in Table 4 . For all currencies, the P-values strongly reject the null 
hypotheses (1) and (2) for lags 10 and 20. The test results indicate unidirectional Granger causality from IV to OP. The combined test results as reported in Tables 3 and 4 confirm the existence of bilateral Granger causality between the OP and IV, which leads to the presence of the chicken-egg issue in the unbiased IV estimation process.

Table 4

Granger Causality Test for IV does not cause OP

\begin{tabular}{|c|c|c|c|c|c|c|c|c|}
\hline \multirow[t]{3}{*}{ Currency } & \multicolumn{4}{|c|}{$\mathrm{IV} \rightarrow \mathrm{CP}$} & \multicolumn{4}{|c|}{$\mathrm{IV} \rightarrow \mathrm{PP}$} \\
\hline & \multicolumn{2}{|c|}{$m=10 \& n=510$} & \multicolumn{2}{|c|}{$m=20 \& n=500$} & \multicolumn{2}{|c|}{$m=10 \& n=510$} & \multicolumn{2}{|c|}{$m=20 \& n=500$} \\
\hline & F-stat & P-value & F-stat & P-value & F-stat & P-value & F-stat & P-value \\
\hline AUD & 3.37 & 0.0003 & 4.14 & 1.E-08 & 2.08 & 0.0245 & 2.16 & 0.0027 \\
\hline $\mathrm{BP}$ & 4.56 & 3.E-06 & 3.97 & 3.E-08 & 3.35 & 0.0003 & 3.02 & 2.E-05 \\
\hline CAD & 4.29 & 9.E-06 & 2.96 & 2.E-05 & 4.17 & 1.E-05 & 3.63 & 3.E-07 \\
\hline EUR & 2.93 & 0.0014 & 1.89 & 0.0114 & 6.04 & 1.E-08 & 3.13 & 8.E-06 \\
\hline JPY & 3.59 & 0.0001 & 2.67 & 0.0001 & 2.26 & 0.0136 & 1.76 & 0.0230 \\
\hline SF & 3.21 & 0.0005 & 2.59 & 0.0002 & 2.96 & 0.0013 & 2.89 & 3.E-05 \\
\hline
\end{tabular}

Next, a "horse race" of the performance of MV vis-à-vis IV is conducted. First, an Ftest analysis is conducted. This test determines the equality of the mean square error (MSE) for pricing call and put options. The test results for 'call pricing MSE equality' and 'put pricing MSE equality' are presented in Table 5. In the 'call pricing MSE equality' analysis, the F-statistic values indicate that $\mathrm{MSE}_{\mathrm{t}, \mathrm{IVC}}$ is statistically different from $\mathrm{MSE}_{\mathrm{t}, \mathrm{MVC}}$ at the onepercent level of significance for all currencies. Further, the F-statistic, at more than unity, implies that $\mathrm{MSE}_{\mathrm{t}, \mathrm{IVC}}$ is larger than $\mathrm{MSE}_{\mathrm{t}, \mathrm{MVC}}$. Similarly, the 'put pricing MSE equality' analysis finds that $\mathrm{MSE}_{\mathrm{t}, \mathrm{IVP}}$ (IV put pricing mean square error) and $\mathrm{MSE}_{\mathrm{t}, \mathrm{MVP}}$ (moneyness volatility put pricing mean square error) are not statistically equal, and $\mathrm{MSE}_{\mathrm{t}, \mathrm{IVP}}$ is larger than $\mathrm{MSE}_{\mathrm{t}, \mathrm{MVP}}$. Overall, the test results indicate that MV outperforms IV in estimating the exchange rate volatility $\left(\sigma_{t}\right)$ for pricing one-day-ahead options using the BS model.

Table 5

F-test Results

\begin{tabular}{|c|c|c|c|c|c|c|}
\hline Currency & \multicolumn{3}{|c|}{ Call Pricing MSE Equality } & \multicolumn{3}{|c|}{ Put Pricing MSE Equality } \\
\hline & $\mathrm{MSE}_{\mathrm{t}, \mathrm{IVC}}$ & $\mathrm{MSE}_{\mathrm{t}, \mathrm{MVC}}$ & F-statistic & $\mathrm{MSE}_{\mathrm{t}, \mathrm{IVP}}$ & $\mathrm{MSE}_{\mathrm{t}, \mathrm{MVP}}$ & F-statistic \\
\hline AUD & $1.94 \mathrm{E}-4$ & $1.49 \mathrm{E}-4$ & $1.2965 * * *$ & $2.00 \mathrm{E}-4$ & $1.99 \mathrm{E}-4$ & $1.0064 * * *$ \\
\hline $\mathrm{BP}$ & $4.52 \mathrm{E}-4$ & $3.71 \mathrm{E}-4$ & $1.2169 * * *$ & $4.52 \mathrm{E}-4$ & $4.24 \mathrm{E}-4$ & $1.0654 * * *$ \\
\hline CAD & $1.48 \mathrm{E}-4$ & $1.26 \mathrm{E}-4$ & $1.1788^{* * *}$ & $1.47 \mathrm{E}-4$ & $1.30 \mathrm{E}-4$ & $1.1277^{* * *}$ \\
\hline EUR & $3.14 \mathrm{E}-4$ & $2.72 \mathrm{E}-4$ & $1.1535^{* * *}$ & $3.15 \mathrm{E}-4$ & $2.87 \mathrm{E}-4$ & $1.0957^{* * *}$ \\
\hline JPY & $1.96 \mathrm{E}-8$ & $1.85 \mathrm{E}-8$ & $1.0585^{* * *}$ & $1.95 \mathrm{E}-8$ & $1.71 \mathrm{E}-8$ & $1.1365^{* * *}$ \\
\hline SF & $1.34 \mathrm{E}-4$ & $1.120 \mathrm{E}-4$ & $1.1127 * * *$ & $1.33 \mathrm{E}-4$ & $1.15 \mathrm{E}-4$ & $1.1572 * * *$ \\
\hline
\end{tabular}

The F-test results are questionable if the pricing errors ( $\mathrm{MSE}_{\mathrm{t}, \mathrm{IVC}}$ and $\mathrm{MSE}_{\mathrm{t}, \mathrm{MVC}}$ or $\mathrm{MSE}_{\mathrm{t}, \mathrm{IVP}}$ and $\mathrm{MSE}_{\mathrm{t}, \mathrm{MVP}}$ ) are contemporaneously correlated with each other. The GrangerNewbold (GN) test accommodates this issue while examining the equality of mean square error (MSE) for pricing call and put options, which is the same approach taken in the F-test. The test results for 'call pricing MSE equality' and 'put pricing MSE equality' are given in Table 6. In the case of the 'call pricing MSE equality' test result, the T-statistic shows that the $\mathrm{MSE}_{\mathrm{t}, \mathrm{IVC}}$ is statistically different from $\mathrm{MSE}_{\mathrm{t}, \mathrm{MVC}}$ at any standard level of significance for all currencies. Further, the positive correlation coefficient confirms that $\mathrm{MSE}_{\mathrm{t}, \mathrm{IVC}}$ has a larger value than that of $\mathrm{MSE}_{\mathrm{t}, \mathrm{MVC}}$. From the analysis of 'put pricing MSE equality', there is a similar conclusion stating that the $\mathrm{MSE}_{\mathrm{t}, \mathrm{IVP}}$ is statistically different from the $\mathrm{MSE}_{\mathrm{t}, \mathrm{MVP}}$ with a 
value higher than $\mathrm{MSE}_{\mathrm{t}, \mathrm{MVP}}$. The GN test results suggest that the MV approach is superior to IV in estimating the value of $\sigma_{t}$ for pricing one-day-ahead options. This is consistent with the F-test results reported in Table 5.

Table 6

Granger-Newbold test results

\begin{tabular}{|c|c|c|c|c|}
\hline \multirow[t]{2}{*}{ Currency } & \multicolumn{2}{|c|}{ Call Pricing MSE Equality } & \multicolumn{2}{|c|}{ Put Pricing MSE Equality } \\
\hline & Correlation Coefficient & T-Statistic & Correlation Coefficient & T-Statistic \\
\hline AUD & 0.3812 & $9.3810^{* * *}$ & 0.3254 & $7.8313 * * *$ \\
\hline $\mathrm{BP}$ & 0.4934 & $12.9112^{* * *}$ & 0.4918 & $12.8561^{* * *}$ \\
\hline CAD & 0.4743 & $12.2611^{* * *}$ & 0.4708 & $12.1468 * * *$ \\
\hline$\overline{\text { EUR }}$ & 0.4647 & $11.9446 * * *$ & 0.4686 & $12.0723^{* * *}$ \\
\hline JPY & 0.5007 & $13.1649 * * *$ & 0.5131 & $13.6064^{* * *}$ \\
\hline SF & 0.4749 & $12.2806^{* * *}$ & 0.5001 & $13.1433^{* * *}$ \\
\hline
\end{tabular}

If one or more of the F-test assumptions as stated in the methodology section are not valid, the Diebold-Mariano (DM) test is appropriate for comparing the equality of mean square error for pricing call and put options. The DM test is conducted based on the call and put pricing differential loss from their pricing mean square errors (MSE). The call pricing error differential loss from $\mathrm{MSE}_{\mathrm{t}, \mathrm{IVC}}$ and $\mathrm{MSE}_{\mathrm{t}, \mathrm{MVC}}$ is estimated by $d_{t}=\left(M S E_{t, I V C}^{4}-M S E_{t, M V C}^{4}\right)$, and the results are presented under the 'call pricing MSE differential loss' in Table 7. The Qstatistic at 15 lags in column (2) indicates that there is no significant autocorrelation in the $\left\{d_{t}\right\}$ series. Apparently, the call pricing mean square errors, $M S E_{t, I V C}$ and $M S E_{t, M V C}$, raised to the fourth power as $M S E_{t, I V C}^{4}$ and $M S E_{t, M V C}^{4}$, respectively, is an appropriate consideration in this circumstance. The T-statistic values in column 3 show that the MSE $_{t, I V C}$ is statistically different from $\mathrm{MSE}_{\mathrm{t}, \mathrm{MVC}}$ at the one percent level of significance for all currency except AUD (five percent level of significance). Further, the positive T-statistic indicating $\mathrm{MSE}_{\mathrm{t}, \mathrm{IVC}}$ holds a larger value than that of $\mathrm{MSE}_{\mathrm{t}, \mathrm{MVC}}$. Similarly, the "put pricing MSE differential loss" analysis concludes that $\mathrm{MSE}_{\mathrm{t}, \mathrm{IVP}}$ and $\mathrm{MSE}_{\mathrm{t}, \mathrm{MVP}}$ are not statistically equal and that the $\mathrm{MSE}_{\mathrm{t}, \mathrm{IVP}}$ is greater in value than that of MSE $\mathrm{t}_{\mathrm{t}, \mathrm{MVP}}$. As a whole, the DM test results show that the MV approach estimates $\sigma_{t}$ more accurately than IV for pricing one-day-ahead options. Further, consistent findings in the series of F-test, GN test and DM test across the six major currency options confirm the validity and reliability of the MV and IV performance evaluation results.

\section{Table 7}

Diebold-Mariano Test Results

\begin{tabular}{|c|c|c|c|c|}
\hline \multirow[t]{2}{*}{ Currency } & \multicolumn{2}{|c|}{ Call Pricing MSE Differential Loss } & \multicolumn{2}{|c|}{ Put Pricing MSE Differential Loss } \\
\hline & $\begin{array}{c}\text { Q-statistic at } 15 \text { lags } \\
\text { (P-values) }\end{array}$ & T-statistics & $\begin{array}{c}\text { Q-statistic at } 15 \text { lags } \\
\text { (P-values) }\end{array}$ & T-statistics \\
\hline AUD & $1.0022(1.000)$ & $2.0967 * *$ & $2.0835(1.000)$ & $2.2249 * *$ \\
\hline $\mathrm{BP}$ & $3.6621(0.999)$ & $2.9671 * * *$ & $3.8136(0.998)$ & $2.9169 * * *$ \\
\hline CAD & $3.7628(0.998)$ & $3.0736 * * *$ & $3.8909(0.998)$ & $3.0500 * * *$ \\
\hline EUR & $3.0565(1.000)$ & $2.8049 * * *$ & $3.1650(0.999)$ & $2.8001 * * *$ \\
\hline JPY & $5.4090(0.988)$ & $3.1224 * * *$ & $4.3736(0.996)$ & $2.9566 * * *$ \\
\hline SF & $3.9448(0.998)$ & $2.9700 * * *$ & $3.1283(0.999)$ & $2.7553 * * *$ \\
\hline
\end{tabular}




\section{Conclusion}

The literature argues that IV is the best predictor of exchange rate volatility for pricing currency options. Researchers also point out that the correct options price estimation requires unbiased IV, and the obtaining of unbiased IV requires options to be priced correctly. The overall IV estimation process is riddled with a chicken-egg dilemma. This study addresses this key issue in two steps. First, it analyses whether the unbiased IV estimation process suffers from the chicken-and-egg problem. Second, an alternate approach to IV is introduced to estimate exchange rate volatility $\left(\sigma_{t}\right)$ for pricing options.

To examine the chicken-egg dilemma, the Granger causality test is employed for OP and IV. The bidirectional causality between OP and IV confirms the presence of the chickenand-egg issue in the unbiased IV estimation process. The alternative approach involves the design of a new measure "moneyness volatility (MV)". The OM identifies whether an option is profitable, neither profitable nor brings a loss or brings a loss from immediate exercise. The OM provides information that affects the pricing of call and put options in the market. For example, at the time of trading, if the call and put options are ITM and OTM, respectively, for the same strike price and maturity, the call market price should be higher than the put market price. Further, the IV is the measure of volatility implied in OPs. Apparently, both the OM and IV contain information regarding the market prices of call and put options; it is thus very reasonable for the volatility obtained from the options' moneyness (i.e. MV) to be considered as an alternative to IV in estimating $\sigma_{t}$ for pricing options.

The F-test, Granger-Newbold (GN) test and Diebold-Mariano (DM) test are employed to evaluate the performance of MV and IV to price currency options appropriately. These tests are also conducted for six major currency options (AUD, BP, CAD, EUR, JP and SF) of WCO traded at the PHLX. Under the F-test, the F-statistic value and the fact that it is greater than unity jointly indicate that the MV outperforms IV in estimating the $\sigma_{t}$ for pricing oneday-ahead options using the BS model. The T-statistic and the positive correlation coefficient of the GN test show results similar to those found by the F-test. Finally, the positive Tstatistic of the DM test confirms the findings reported by the F-test and GN test. The consistency of this series of three test results across six major currency options reveals the validity as well as the reliability of the outcomes of the MV and IV performance assessments. The MV approach overcomes the pitfalls encountered with IV in estimating $\sigma_{t}$ for pricing currency options accurately.

Apart from the chicken-and-egg issue, the limitations of the IV estimation process are as follows: (1) estimating the unbiased IV requires the ATM options price (see equations 3 and 4), and (2) averaging the call and put's IV (see equation 5). The MV approach also overcomes these limitations. This study provides a unique solution for pricing one day ahead currency options. Further, Kazantzis and Tessaromatis (2001) find that IV is generally better than historic volatility forecasts for horizons ranging from one day to three months. Using the OTC currency options price, Christoffersen and Mazzotta (2005) suggest that IV provides largely unbiased and fairly accurate forecasts of the actual volatility one month and three months ahead. Before the launching of WCO in PHLX, the options traded only had a maturity of three months. Thus the performance of MV vis-à-vis IV for pricing options with a maturity of three months is an open issue. This is left for future research. 


\section{References}

Black, F \& Scholes, M 1973, 'The pricing of options and corporate liabilities', Journal of Political Economy, vol.83, pp637-705. http://dx.doi.org/10.1086/260062

Chang, EJ \& Tabak, BM 2007, 'Are implied volatilities more informative? The Brazilian real exchange rate case', Applied Financial Economics, vol.17 pp569-576. http://dx.doi.org/10.1080/09603100600706758

Christoffersen, P \& Mazzotta, S 2005, 'The accuracy of density forecasts from foreign exchange options', Journal of Financial Econometrics, vol.3, pp578-605. http://dx.doi.org/10.1093/jjfinec/nbi021

Dickey, DA \& Fuller, WA 1979, 'Distribution of the estimators for autoregressive time series with a unit root', Journal of the American Statistical Association, vol.74, pp427-431.

Diebold, FX \& Mariano, RS 1995, 'Comparing predictive accuracy', Journal of Business and Economic Statistics, vol.13, pp253-263.

Ederington, LH \& Guan, W 2006, 'Measuring historical volatility', Journal of Applied Finance, vol.16, pp5-14.

Gospodinov, N, Gavala, A \& Jiang, D 2006, 'Forecasting volatility', Journal of Forecasting, vol.25, pp381-400. http://dx.doi.org/10.1002/for.993

Granger, C \& Newbold, P 1976,'Forecasting transformed series', Journal of the Royal Statistical Society, vol.B38, pp189-203.

Hoque, A 2010, 'World currency options market efficiency', Banks and Bank Systems, vol. 5, no. 2, pp173-178.

Hoque, A, Chan, F \& Manzur M, 2008, 'Efficiency of the foreign currency options market. Global Finance Journal, vol.19, pp157-170. http://dx.doi.org/10.1016/j.gfj.2008.02.002

Hoque, A \& Krishnamurti, C 2012, 'Modeling moneyness volatility in measuring exchange rate volatility, International Journal of Managerial Finance, vol. 8, pp365-380. http://dx.doi.org/10.1108/17439131211261279

Jorion, P 1995, 'Predicting volatility in the foreign exchange market', Journal of Finance, vol.50, pp507-528. http://dx.doi.org/10.1111/j.1540-6261.1995.tb04793.x

Kazantzis, CI. \& Tessaromatis, NP 2001, 'Volatility in currency market', Managerial Finance, vol.27, pp1-22. http://dx.doi.org/10.1108/03074350110767204

Kwaitkowski, D, Phillips, P, Schmidt, P \& Shin, Y 1992, 'Testing the null hypothesis of stationary against the alternative of a unit root', Journal of Econometrics, vol.54, pp159-178. http://dx.doi.org/10.1016/0304-4076(92)90104-Y

$\mathrm{Li}, \mathrm{M}$ 2008, 'Approximate inversion of the Black-Scholes formula using rational functions', European Journal of Operational Research, vol. 185, no. 2, pp.743-759. http://dx.doi.org/10.1016/j.ejor.2006.12.028

Merton, RC 1973, 'Theory of rational option pricing', The Bell Journal of Economics and Management Science, vol.4, pp141-183. http://dx.doi.org/10.2307/3003143

Offshore A-Letter, 2007, 'A new era in currency trading begins today'. The Sovereign Society, vol.9, pp1-2.

Pong, S, Shackleton, MB, Taylor, SJ \& Xu, X 2004, 'Forecasting currency volatility: A comparison of implied volatility and AR(FI)MA models', Journal of Banking and Finance, vol.28, pp2541-2563. http://dx.doi.org/10.1016/j.jbankfin.2003.10.015 
Phillips, P \& Perron, P 1988, 'Testing for a unit root in time series regression', Biometrika, vol.75, pp335-346. http://dx.doi.org/10.1093/biomet/75.2.335

Press, WH, Flannery, BP, Teukolsky, SA \& Vetterling, WT 1992, Numerical Recipes in C: The Art of Scientific Computing, Cambridge University Press, Cambridge.

Quantitative Micro Software, 2007, EViews 6 User's Guide I, p411.

Scott, E \& Tucker, AL 1989, 'Predicting currency return volatility', Journal of Banking and Finance, vol.13, pp839-851. http://dx.doi.org/10.1016/0378-4266(89)90005-8

$\mathrm{Xu}, \mathrm{X}$ \& Taylor, SJ 1994, The term structure of volatility implied by foreign exchange options', Journal of Financial and Quantitative Analysis vol.29, pp57-74. http://dx.doi.org/10.2307/2331190 
AABFJ | Volume 7, no. 2, 2013 